\title{
Wellbeing of professionals at entry into the labour market: a follow up survey of medicine and architecture students
}

\author{
P Virtanen, A-M Koivisto
}

\begin{abstract}
Study objective-Knowledge about changes in wellbeing during the passage from professional studies to working life is scarce and controversial. This study examined these changes among university graduates with good and poor employment prospects.
\end{abstract}

Design-A longitudinal study with four postal questionnaire surveys of a closed cohort.

Setting-Cohorts of graduating Finnish physicians and architects were followed up from 1994 to 1998. In 1994 Finland's national economy was still struggling to break loose from a period of severe recession, and unemployment rates were high even among educated professionals. As economic growth eventually got under way the unemployment situation began to ease for physicians but not for architects. Participants-Architecture students ( $\mathrm{n}=$ 189) from Finland's three technical universities and medical students $(n=638)$ from Finland's five medical faculties. Both had started their studies in 1989.

Results-In the first questionnaire survey there were no differences between the professions in strain resistance resources, as indicated by Sense of Coherence (SOC), or in psychological distress, as indicated by General Health Questionnaire (GHQ). Profession emerged as a significant between subject factor in analysis of variance for repeated measures of both SOC and GHQ. Physicians' scores on the 13 item SOC questionnaire improved during the follow up from 62.6 to 67.5 and on the 12 item GHQ questionnaire from 24.2 to 22.2. Among architects the corresponding scores remained unchanged (62.5-62.2 and 23.1-22.6). The significance of profession remained unchanged when gender and individuals' graduation and total work experience were introduced to the statistical models as between subject factors.

Conclusions-Improved SOC in physicians but not in architects supports the hypothesis that good employment prospects are important to employee wellbeing. Although less consistent, indicating fluctuations in day to day psychological distress, GHQ findings are also in line with the hypothesis. In both professions the indicators studied were independent of individuals' graduation and career. It is concluded that rather than individually, the mechanisms that connect employment prospects with wellbeing operate collectively within the whole profession. Highly educated professionals do not complete their studies until almost 30, and if for reasons of insecure employment they are unable to develop their SOC to the optimum level at that age, their resources for resisting health endangering strain may remain permanently poor.

(F Epidemiol Community Health 2001;55:831-835)

Entry into the labour market is one of the important changes in a person's life span. It may be seen as a normative crisis that fulfils a basic norm of labour market citizenship. ${ }^{1}$ Employment therefore also increases the person's psychosocial wellbeing. The crucial significance of work to wellbeing has been studied particularly in the context of unemployment research. Most of the positive elements of work, for instance those articulated by Jahoda ${ }^{2}$ and Warr, ${ }^{3}$ are also relevant in the case of young people who are entering in their first job. However, the beginning of a professional career may involve stressful experiences. The relative freedom of student life is replaced by new kinds of responsibilities, and there may be problems in integrating into the social collectivity at work and uncertainty about your knowledge and skills.

Fixed term contracts and unemployment periods are the rule rather than an exception among young employees. ${ }^{1}$ An objectively insecure situation is unlikely to cause them very much subjective insecurity and stress unless it is perceived as "too precarious" or unless the career prospects seem "too poor". Ezzy's ${ }^{4}$ view of the working career as status passages is most relevant in youth when both the characteristics of work and labour market status evidently have more variable and more specific significance to individuals than in middle age. Australian studies ${ }^{5}{ }^{6}$ have shown that dissatisfaction with the job is associated with poor mental health at least as strongly as unemployment at age 16-25. In Graetz's ${ }^{6}$ study job satisfaction was assessed globally, with one question, and apart from immediate working conditions the question no doubt also comprises prospects for finding the desired career.

A good education means a secure career, and highly educated people have appeared as an "academically interesting" rather than a "socially important" group in research on underemployment. Within the limited body of 


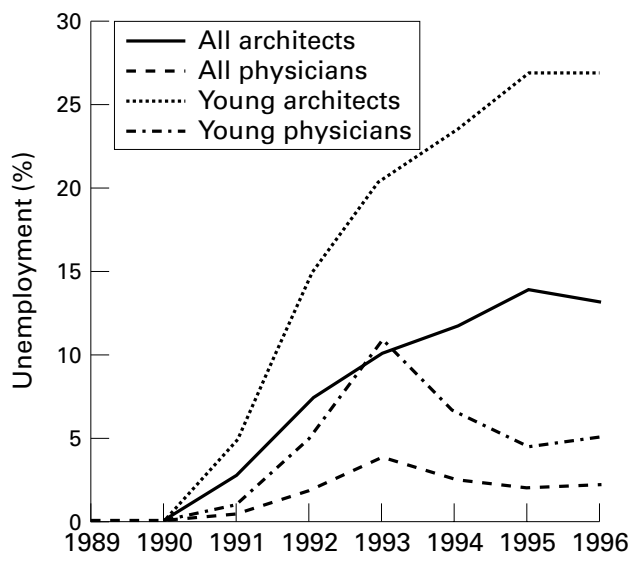

Figure 1 Physicians' and architects' unemployment rates in Finland in 1989-1996. "Young" = those who have graduated less than five years ago.

research that is available, older studies ${ }^{78}$ show that poor employment is associated with low wellbeing among highly educated professionals as well as among less educated workers. However, a more recent Dutch study ${ }^{9}$ found a causal association between unemployment and poor mental health among school leavers but not among more educated college graduates. The finding is interpreted against the national situation at the time of the study: "Unemployment not only has different effects in different occupational groups; in addition, as suggested by Winefield and Fryer, ${ }^{10}$ the specific societal and historical context seems to play a role as well". Economic fluctuations may be considered the basis of this context: at times of economic depression employment insecurity is real threat in the white collar class as well.

This study of young Finnish physicians and architects was started in 1994. Finland's national economy ran into an exceptionally severe crisis at the beginning of the 1990 s, and unemployment began to rise sharply ${ }^{11}$ ( fig 1). This situation of general job insecurity even among highly educated professionals provided the impetus for a follow up study of wellbeing among graduating architecture and medical students.

Graduation has traditionally meant different things to these two groups of professionals. For physicians graduation is necessary so that they can gain a licence to practise medicine, whereas architects may be "mature" experts even if they have not yet formally graduated. In fact, at times of good employment architects' graduation is commonly delayed because of moving over to work, but when there is shortage of jobs they have no other option but to continue with their studies.

Figure 1 shows that the recession had only a minor and transitory impact on physicians'

Table 1 Study subjects by gender and profession, and response rate in the follow up surveys

\begin{tabular}{lrlllll}
\hline & \multicolumn{7}{c}{ Response rate (\%) } \\
\cline { 6 - 7 } & Men & Woman & 1994 & 1995 & 1996 & \multirow{2}{*}{1998} \\
\hline Physicians (n=638) & 273 & 365 & & & & \\
percentage & 43 & 57 & 79 & 72 & 69 & 69 \\
Architects (n=189) & 107 & 82 & 71 & 68 & 67 & 61 \\
percentage & 57 & 43 & 71 & 68 & \\
\hline
\end{tabular}

employment whereas architects were among the hardest hit of the highly educated professions. The "natural experiment" designed by the labour markets thus dictated the hypothesis of this study: wellbeing improves during the passage from university to work but this improvement is less pronounced among professionals with poor employment prospects.

The study also had an aim concerning the nature of the Sense of Coherence (SOC) concept. We asked two questions:

- does this "salutogenic resistance resource"12 attain its "adult" level during the period of entry into the labour market also among those studying to a relatively high age?

- does the development of SOC depend on employment prospects?

\section{Methods}

THE STUDY GROUP

A questionnaire survey was conducted at the end of 1994 among students who had started their studies in Finland's three technical universities and five medical faculties in 1989 (table 1). In the covering letter they were informed about the background and aims of the follow up study, which was to include three further postal questionnaire surveys in the following years.

The response rate declined during the follow up from $79 \%$ to $69 \%$ in physicians and from $71 \%$ to $61 \%$ in architects (table 1 ). The cohort studied consists of the 346 physicians and 81 architects who responded to all four questionnaires. In this cohort the physicians' mean age at the beginning of the follow up was 26.1 (SD 3.1 ) and $223(64 \%)$ of them were women. Among architects the corresponding figures were 26.0 (SD 3.3) and 35 (43\%).

The first possible graduation year of the cohorts was 1995, and half of the physicians but just 1 in 10 architects had graduated by the end of 1995. In the last follow up survey in 1998 more than 9 in 10 of the physicians and about half of the architects had graduated (table 2).

\section{STATUS PASSAGE}

The status passage from student to professional consists of two elements: formal graduation and entry to work.

The inherent difference between the graduation rates of the two professions was taken into account by including a categoric variable that classified as "rapid students" those physicians who graduated in 1995 and architects who had graduated by 1998, and as "slow students" the rest of the professionals.

Physicians had significantly more work experience than architects (table 2). This was also taken into account with a categoric variable that distinguished between respondents with much (more than the average for the respective profession and gender) and little work experience. Unemployment was not used as a factor in explaining psychosocial wellbeing because the cohorts followed up did not differ in their unemployment experiences (table 2). 
Table 2 Graduation and labour market experience during the follow up period by profession

\begin{tabular}{lll}
\hline & Physicians & Architects \\
\hline $\begin{array}{ll}\text { Graduated in } \\
1995\end{array}$ & $45.6 \%$ & $10.9 \%$ \\
1996 & $83.3 \%$ & $15.9 \%$ \\
$\quad 1998$ & $93.9 \%$ & $45.2 \%$ \\
$\begin{array}{l}\text { Work experience } \\
\text { mean }\end{array}$ & 23.4 & 14.1 \\
$\quad$ range & $0-35$ months & $0-35$ months \\
$\quad$ SD & 8.4 & 9.9 \\
Unemployment experience & $0-6$ months & $0-8$ months \\
$\quad$ range & $87.3 \%$ & $86.4 \%$ \\
$\quad$ no unemployment & & \\
\hline
\end{tabular}

THE OUTCOME MEASURES

Labour markets and status passage constituted the structural preconditions for wellbeing of the cohorts studied. At the individual level wellbeing was approached from two points of view: strain resistance resources as conceptualised and operationalised with the SOC questionnaire, and psychological distress as conceptualised and operationalised with the General Health Questionnaire (GHQ).

According to Antonovsky ${ }^{12}$ people vary with respect to their "general strain resistance resources". For people with good resources it is easier to cope successfully with potentially health endangering stressing experiences and to pass them without adverse consequences to health. This theoretical idea is explicated as SOC, or a person's capacity for manageability, comprehensibility, and meaningfulness. SOC is akin to several other conceptualisations of personality, ${ }^{13}$ and it is regarded as a relatively permanent property of an adult individual. Although relatively old, the participants of this study were just beginning to reach independence as labour market adults, and we were interested in studying the "maturation" of SOC at this stage of life. On the other hand, "salutogenesis" associated with strong SOC justifies its use as an outcome measure indicating preconditions for health. The 13 item version of the SOC questionnaire with a Likert scale from 1 to 7 was used. ${ }^{14}$

In contrast with $\mathrm{SOC}$, which assesses your longer term orientation to the world inside and outside of oneself, the focus of the $\mathrm{GHQ}^{15}$ is on the person's capacity in everyday life and on mental wellbeing during the past few weeks. It is highly sensitive to the psychological distress the respondent is actually perceiving. The method has been widely used in studies concerning employment related and occupational problems. ${ }^{16}$ The 12 item version of the
GHQ with a Likert scale from 1 to 4 was applied.

\section{STATISTICAL METHODS}

Changes in SOC and GHQ were evaluated by analysis of variance for repeated measures. The analysis was carried out as follows. Firstly, time was used as the within subject factor to see whether there were any changes in SOC or GHQ during the study period. Secondly, profession was entered in the model as a between subject factor to see whether the change in SOC or GHQ was different between physicians and architects. Thirdly, to establish whether factors other than profession have any effect on the change, gender, graduation and work experience were introduced in the model as separate between subject factors together with profession, and we then tried also a model including all variables. The independent effect of these third stage factors on the outcome measures was of minor interest, the reason we wanted to control them was to get more convincing evidence on the effect of profession. Annual differences in SOC and GHQ between professions and sexes were assessed using two sample $t$ test with Bonferroni correction, where $\mathrm{p}<0.01$ was considered as statistically significant. SPSS for Windows version 9.0. statistical software was used in the analyses.

\section{Results}

STRAIN RESISTANCE RESOURCES

Analysis of variance for repeated measures showed that the change in SOC (table 3) was highly significant for the whole follow up period. Profession was associated with change while gender, graduation, and work experience were insignificant-both when introduced in the model as separate between subject factors and when introduced simultaneously.

The difference in the initial SOC scores between the professions (table 3) was not statistically significant, but in the subsequent three surveys the difference was highly significant. Gender differences were statistically insignificant among both professions.

At the end of the follow up SOC tended to be higher in those who had graduated slowly and in those who had little work experience (table 3), but the differences were not statistically significant.

PSYCHOLOGICAL DISTRESS

The change in the GHQ score (table 4) was highly significant in analysis of variance for

Table 3 Sense of coherence scores (mean (SD)) by year, profession and gender, and by graduation and work experience

\begin{tabular}{|c|c|c|c|c|c|c|c|c|}
\hline & \multirow[b]{2}{*}{1994} & \multirow[b]{2}{*}{1995} & \multirow[b]{2}{*}{1996} & \multirow[b]{2}{*}{1998} & \multicolumn{2}{|l|}{ Graduation } & \multicolumn{2}{|c|}{ Work experience by 1998} \\
\hline & & & & & Rapid & Slow & Much & Little \\
\hline All ${ }^{\star}$ & $62.6(10.1)$ & $64.3(9.4)$ & $64.6(10.3)$ & $66.4(10.3)$ & $65.5(10.3)$ & $67.3(10.1)$ & $66.3(9.5)$ & $66.4(11.0)$ \\
\hline \multirow{3}{*}{$\begin{array}{l}\text { Physicians } \nmid \ddagger \\
\text { men } \\
\text { women }\end{array}$} & $62.6(9.9)$ & $65.0(9.2)$ & $65.3(9.9)$ & $67.5(9.8)$ & $66.6(10.0)$ & $68.1(9.5)$ & $67.4(9.1)$ & $67.3(10.5)$ \\
\hline & $64.3(9.7)$ & $66.5(9.5)$ & $66.5(10.5)$ & $69.0(9.9)$ & & & & \\
\hline & $61.6(9.9)$ & $64.1(9.0)$ & $64.7(9.6)$ & $66.4(9.6)$ & & & & \\
\hline \multirow{3}{*}{$\begin{array}{l}\text { Architects } † \ddagger \\
\text { men } \\
\text { women }\end{array}$} & $62.5(10.8)$ & $61.4(9.9)$ & $61.6(11.2)$ & $62.2(11.3)$ & $60.9(10.6)$ & $63.8(11.9)$ & $61.5(10.2)$ & $63.0(12.3)$ \\
\hline & $61.7(11.8)$ & $60.6(9.9)$ & $60.1(9.7)$ & $60.4(8.9)$ & & & & \\
\hline & $63.5(9.4)$ & $62.4(9.9)$ & $63.5(9.7)$ & $64.6(8.9)$ & & & & \\
\hline
\end{tabular}

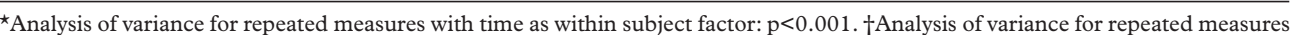
with time as within subject factor and profession as between subject factor: $\mathrm{p}=0.002$ (time), $\mathrm{p}=0.005$ (profession), $\mathrm{p}<0.004$ (time $\times$ profession). $\ddagger t$ Test for the difference between physicians and architects: $1994 \mathrm{p}=0.920,1995 \mathrm{p}=0.002,1996 \mathrm{p}=0.003,1998$ $\mathrm{p}<0.001$. 
Table 4 Psychological distress (mean (SD) of General Health Questionnaire) by year, profession and gender, and by graduation and work experience

\begin{tabular}{|c|c|c|c|c|c|c|c|c|}
\hline & \multirow[b]{2}{*}{1994} & \multirow[b]{2}{*}{1995} & \multirow[b]{2}{*}{1996} & \multirow[b]{2}{*}{1998} & \multicolumn{2}{|l|}{ Graduation } & \multicolumn{2}{|c|}{ Work experience by 1998} \\
\hline & & & & & Rapid & Slow & Much & Little \\
\hline $\mathrm{All}^{\star}$ & $24.0(5.4)$ & $23.0(5.0)$ & $23.1(5.3)$ & $22.3(4.8)$ & $22.4(4.7)$ & $22.2(4.8)$ & $22.5(4.7)$ & $22.1(4.9)$ \\
\hline \multirow{3}{*}{$\begin{array}{l}\text { Physicianstł } \\
\text { men } \\
\text { women }\end{array}$} & $24.2(5.3)$ & $22.7(4.7)$ & $22.9(5.1)$ & $22.2(4.7)$ & $22.2(4.5)$ & $22.3(4.9)$ & $22.5(4.7)$ & $21.9(4.6)$ \\
\hline & $23.3(4.2)$ & $22.5(4.4)$ & $22.8(4.9)$ & $22.5(4.6)$ & & & & \\
\hline & $24.7(5.7)$ & $22.8(4.8)$ & $23.0(5.2)$ & $22.1(4.7)$ & & & & \\
\hline \multirow{3}{*}{$\begin{array}{l}\text { Architects } † \ddagger \\
\text { men } \\
\text { women }\end{array}$} & $23.1(5.8)$ & $24.1(6.0)$ & $23.8(6.3)$ & $22.6(5.2)$ & $23.5(5.7)$ & $21.6(4.6)$ & $22.4(4.5)$ & $22.9(5.9)$ \\
\hline & $22.9(5.3)$ & $24.4(6.4)$ & $25.2(7.1)$ & $22.5(5.1)$ & & & & \\
\hline & $23.5(6.4)$ & $23.7(5.6)$ & $22.1(4.6)$ & $22.8(5.5)$ & & & & \\
\hline
\end{tabular}

*Analysis of variance for repeated measures with time as within subject factor: $\mathrm{p}<0.001$. †Analysis of variance for repeated measures with time as within subject factor and profession as between subject factor: $\mathrm{p}=0.007$ (time), $\mathrm{p}=0.466$ (profession), $\mathrm{p}=0.004$ (time $\times$ profession). $\ddagger t$ Test for the difference between physicians and architects: $1994 \mathrm{p}=0.109,1995 \mathrm{p}=0.024,1996 \mathrm{p}=0.159,1998$ $\mathrm{p}=0.496$.

repeated measures for the whole study group. Profession and gender $(\mathrm{p}=0.003)$ had a significant and graduation and work experience an insignificant effect on the change when entered one by one in the model as between subject factors. The result was similar when all four factors were entered in the model simultaneously.

Studied as annual cross sections, the differences in GHQ scores both between the two professions and between the sexes were statistically insignificant (table 4 ).

The GHQ scores at the end of the follow up were not associated with graduation or work experience (table 4). Even the relatively high score indicating higher psychological distress among graduated than ungraduated architects was not statistically significant.

\section{Discussion}

The response rate in the first follow up survey was high, and although 215 (34\%) of the 639 respondents dropped out from at least one of the subsequent surveys the cohorts of this study came to comprise more than half of the original study group. The representativity of the cohorts is supported by the fact that in the first questionnaire they did not differ with respect to the outcome measures from the respondents who dropped out: among physicians in the cohort the GHQ score was 24.2 , in the drop outs 23.5 ; the SOC scores were 62.6 and 63.4, respectively. Among architects the corresponding figures were 23.2 and 23.4, and 62.3 and 62.6 .

Several studies ${ }^{6}{ }^{17-19}$ suggest that less successful entry into the labour market, especially unemployment, is associated with poor psychological and psychosomatic health among school leavers. Although the university graduates in this study were quite old, they were in a similar status passage situation. The aim here was to find out whether wellbeing develops differently between professions with good (physicians) and poor (architects) employment prospects. By controlling for graduation and employment career we wanted to find out whether there are structural factors, or historical, societal and economic contexts as understood by Schaufeli ${ }^{9}$ that affect the psychosocial wellbeing independently of a person's personal labour market experiences.

The person's psychosocial wellbeing is obviously affected by events and changing circumstances at this particular stage of life: marriages and childbirths, improving standard of living, support and strain from social collectives at work, and so on. To what extent then can the observed changes be attributed to the two professions' different career prospects? It is fair to suggest that the context presented in the covering letter and the issues of the questionnaire have oriented the respondents to thinking specifically about the significance of work and career as a source of welfare, wellbeing, and health.

Improved SOC among physicians but not among architects may be attributed to the professions' different employment prospects. The result supports the first hypothesis of our study. The findings on GHQ are less consistent, but none the less more in line with the hypothesis than opposed to it. The relatively high GHQ score recorded for female physicians in the first survey probably indicates anxiety about their professional competence at the end of their studies. Because of the economic recession it was very difficult for this generation of medical students to get jobs during holidays, and especially women lacked the experience in medical practice that students "normally" acquire. ${ }^{20}$ It is merely male architects' high GHQ scores in second and third survey that may be attributed to the poor employment situation.

The theory suggests that the SOC is a personality trait that does not mature until about age $30,,^{21}$ depending crucially on experiences and conditions of working life. ${ }^{2324}$ The period during which SOC attains its optimal level is quite narrow among those who study up to relatively high age. This study sheds new light on the development of SOC in these people.

Poor employment prospects seem to prevent an improvement in SOC even among architects who have graduated relatively quickly and who have a relative abundance of work experience, and vice versa: SOC also improves in physicians whose studies are prolonged and whose entry into work is delayed. These results point that age and work experience are not sufficient conditions for SOC to reach a "mature" level, but good employment prospects are also needed. This indicates that the stabilisation of SOC does not take place merely through a person's unique life events but in a historical context, in relation to (sub)cultural, social, and economic factors. We may talk about the SOC of a group, in our case a profession, which is 
KEY POINTS

- Studies concerning health consequences of employment trajectories should take into account the macroeconomic conjunctures and unemployment rate.

- The collective employment security of a profession is an important determinant of wellbeing at entry into the labour market.

- A person's Sense of Coherence improves and psychological distress decreases in the early phases of the professional careers, but only if the employment prospects are good.

- Policy programmes aimed at improving employment security among youths could both promote actual mental health and provide resources for staying healthy.

influenced by collective experiences of employment security.

This study shows the development of SOC at an individual and at group level, but the study may also been seen as an attempt to meet the theoretical challenge with which Antonovsky concludes the article that remained his last ${ }^{25}$ : we think we have demonstrated how collective SOC is created in interdependence between the individual and the collective.

In conclusion, uncertainty about future employment has adverse consequences in white collar professions as well, ${ }^{26}$ and young professionals in particular seem to need a sense of "collective employment security" during their first years in the labour markets in order to develop strong SOC. If this early career is characterised by insecure entry into work, their SOC will perhaps never reach the optimal level. This, again, means a scarcity of resources with which to resist the strain caused by the inevitable status passages people experience in the flexible-that is, permanently precariuous, labour working life of post-industrial society.

In terms of policy implications what this means is that the government should support the employment of young people graduating from schools and universities. Youth employment programmes not only reduce costs and social problems by promoting professional development and social integration, but they can guarantee good health and optimal control of stress among working people.

Funding: none.

Conflicts of interest: none.
1 Suikkanen A, Viinamäki L. New dimensions of labour market citizenship. In: Ferrie J, et al, eds. Labour market changes and job insecurity. A challenge for social welfare and health promotion. Copenhagen: WHO Regional Publications, European Series, No 81, 1999:31-58.

2 Jahoda M. Employment and unemployment: a socialpsychological analysis. Cambridge: Cambridge University Press, 1982.

3 Warr P. Work, unemployment, and mental health. Oxford: Clarendon Press, 1987.

4 Ezzy D. Unemployment and mental health: a critical review. Soc Sci Med 1993;37:41-52.

5 Winefield A, Tiggemann M, Winefield $\mathrm{H}$. The psychological impact of unemployment and unsatisfactory employment in young men and women: longitudinal and cross-sectional data. Br F Psychol 1991;82:473-86.

6 Graetz B. Health consequences of employment and unemployment: longitudinal evidence for young men and women. Soc Sci Med 1993;36:715-24.

7 Kaufman H. Professionals in the search of work: coping with the stress of job loss and underemployment. New York: Wiley, 1982 .

8 Feather N, Bond M. Time structure and purposeful activity among employed and unemployed university graduates. $\mathcal{F}$ Occup Psychol 1983;56:241-54.

9 Schaufeli W. Youth unemployment and mental health: some Dutch findings. $\mathcal{F}$ Adolesc 1997;20:281-92.

10 Winefield A, Fryer D. Some emerging threats to the validity of research on unemployment and mental health. Australian Fournal of Social Research 1996;2:115-28.

11 Havén, H. Työttömyys tutkinnon jälkeen 1989-1996. [Unemployment after graduation 1989-1996]. Helsinki: Tilastokeskus, 1997.

12 Antonovsky A. Unraveling the mystery of health. How people manage stress and stay well. San Francisco: Jossey-Bass, manage 1987.

13 Sullivan G. Towards clarification of convergent concepts: sense of coherence, will to meaning, locus of control, learned helplessness and hardiness. F Adv Nurs 1993;18: 1772-8.

14 Antonovsky A. The structure and properties of the Sense of Coherence scale. Soc Sci Med 1993;36:725-33.

15 Goldberg D. The detection of psychiatric illness by questionnaire. A technique for the identification and assessment of nonpsychotic psychiatric disease. Oxford: Oxford University Press, 1972 .

16 Banks H, Clegg W, Jackson R, et al. The use of general health questionnaire as an indicator of mental health in occupational studies. F Occup Psychol 1980;53:187-94.

17 Tiggeman $M$, Winefield A. The effects of unemployment on the mood, self-esteem, locus of control, and depressive affect of school leavers. F Occup Psychol 1984;57:33-42.

18 Hammarstrom A, Janlert U. Nervous and depressive symptoms in a longitudinal study of youth unemployment selection or exposure? F Adolesc 1997; 20:293-305.

19 Prause J, Dooley D. Effect of underemployment on schoolleavers' self-esteem. F Adolesc 1997;20:243-60.

20 Heino J, Virtanen P. Yli puolet valmistuneista lääkäreistä vailla työkokemusta. [Over half of graduated physicians have no work experience]. Suomen Lääkärilehti 1995;50: 3345-8.

21 Sagy S, Antonovsky A, Adler I. Explaining life satisfaction in later life: the sense of coherence model and activity theory. Behaviour, Health and Ageing 1990;1:11-25.

22 Antonovsky A. The structural sources of salutogenic strengths. In: Cooper C, Payne R, eds. Personality and stress: individual differences in the stress process. Chichester: Wiley, 1991:67-104.

23 Antonovsky A. Health promoting factors at work: the Sense of Coherence. In: Kalimo R, El-Batawi M, Cooper C, eds. Psychosocial factors at work. Geneva: WHO, 1987:153-67.

24 Kalimo R, Vuori J. Work and Sense of Coherenceresources for competence and life satisfaction. Behav Med 1990;16:76-89.

25 Antonovsky A. The sense of coherence, an historical and future perspective. Israeli fournal of Medical Science 1966;32:170-8

26 Ferrie J, Shipley M, Marmot M, et al. An uncertain future: the health effects of threats to employment security in white collar men and women. Am f Public Health 1998;88: 1030-6. 